\title{
DESAIN BREAKWATER SISI MIRING SEBAGAI UPAYA MENGANTISIPASI LIMPASAN AIR LAUT PADA BANGUNAN REVETMENT DI PANTAI MALABERO KOTA BENGKULU
}

\author{
Welendri Yannovita ${ }^{1)}$, Besperi $^{2)}$, Gusta Gunawan ${ }^{3)}$ \\ ${ }^{122) 3)}$ Program Studi Teknik Sipil, Fakultas Teknik UNIB, Jl. W. R. Supratman, \\ Kandang Limun, Bengkulu 38371, Telp. (0736)344087 \\ email: whellendrian20@gmail.com
}

\begin{abstract}
Abstrak
Penelitian ini bertujuan merencanakan bangunan pemecah gelombang dan berat batu lapis menggunakan batu pecah di Pantai Malabero Kota Bengkulu. Pengumpulan data dilakukan secara primer dan secara sekunder. Metode pengolahan data primer yang digunakan yaitu survei langsung di lapangan (Hs dan Ts) sedangkan data sekunder menggunakan metode analisis data angin, analisis data pasang surut dan topografi. Hasil dari perhitungan penelitian breakwater mempunyai elevasi puncak 5,55 m, lebar puncak 3,71 m pada bagian kepala dan 3,91 m pada bagian lengan. Berat unit lapis pelindung breakwater bagian kepala $\mathrm{W}=3,331$ ton $\mathrm{W} / 10=331 \mathrm{~kg}$ $\mathrm{W} / 200=16 \mathrm{~kg}$ dan bagian lengan $\mathrm{W}=3,87 \mathrm{ton}, \mathrm{W} / 10=387 \mathrm{~kg} \mathrm{~W} / 200=19 \mathrm{~kg}$. Jumlah lapis pelindung tiap $10 \mathrm{~m}^{2}$ sebanyak 13 buah untuk di kepala dan 12 buah untuk di lengan.
\end{abstract}

Kata kunci: pantai malabero, breakwater

\begin{abstract}
This research aims to desaign of sideways breakwater as an effort to anticipate the water overflow On The Revetment Building At Malabero Beach Bengkulu City. The data used is primary data and secondary data. Primary Data Processing Method Used in Field Direct Namely Collection (Hs and Ts), while the secondary data analysis method using wind data, analysis data tides and topography. The results of the breakwater have the elevation Of 5,55m, width 3,71 $\mathrm{m}$ on the head and 3,91 $\mathrm{m}$ on the arms. Weight unit protective cover breakwater head $W=3,31$ tons, $W / 10=331 \mathrm{~kg}, W / 200=16 \mathrm{~kg}$ and the arms $W=3,87$ tons, $W / 10=387 \mathrm{~kg}, W / 200=19 \mathrm{~kg}$. With 13 and 12 slides of cover in each $10 \mathrm{~m}^{2}$ on the head and arm.
\end{abstract}

Keywords: malabero beach, breakwater 


\section{PENDAHULUAN}

Pantai Malabero telah banyak mengalami kerusakan berupa perubahan garis pantai akibat abrasi. Besarnya hempasan gelombang merupakan salah satu faktor penyebab mudahnya kawasan tersebut mengalami erosi dan overtopping. Permasalahan yang terjadi di kawasan tersebut perlu dicarikan solusi bagaimana upaya menghindari overtopping pada bangunan revetment, karena akibat adanya overtopping konstruksi akan mengalami gerusan pada bagian belakang yang mengakibatkan konstruksi menjadi labil bahkan hancur.

Pemerintah setempat telah berupaya untuk mencegah semakin besarnya kerusakan dan penyempitan wilayah daratan. Salah satu cara yaitu dengan menggunakan konstruksi pengaman pantai dalam bentuk konstruksi revetment, akan tetapi sudah mengalami kerusakan dan sedimentasi sehingga rawan mengalami overtopping.

Pada kajian ini peneliti tertarik mendesain bangunan pemecah gelombang pada lokasi dengan batu buatan breakwater menggunakan material batu alam di sejajar pantai.

Syahputra (2014) melakukan penelitian tentang analisis struktur bangunan breakwater tipe di Tapak Paderi Kota Bengkulu. Refi (2013) dengan menganalisis bangunan breakwater dengan menggunakan armor batu, tetrapod, dan a-jack. Handika (2017) melakukan penelitian tentang redesign bangunan pemecah gelombang (breakwater) tipe campuran pantai sungai suci kabupaten bengkulu tengah. Oleh sebab itu peneliti tertarik untuk melakukan perencanaan terhadap bangunan pengaman pantai yang sudah ada dengan menambahkan bangunan pemecah gelombang menggunakan breakwater sisi miring. Analisis dilakukan dengan memperhitungkan gaya alam seperti pasang surut dan tinggi gelombang untuk mendapatkan desain yang ideal.

\section{Pantai}

Pantai adalah daerah perairan (laut atau danau yang dibatasi oleh surut terendah dan pasang tertinggi, sedangkan laut adalah daerah perairan yang dibatasi air surut sampai ke kedalaman tertentu. Ditinjau dari profil pantai, daerah ke arah pantai dari garis gelombang pecah dibagi menjadi tiga daerah yaitu inshore, foreshore dan backshore (Umar, 2011).

\section{Konversi kecepatan angin}

Angin yang berhembus diatas permukaan air akan memindahkan energi air. Kecepatan angin akan menimbulkan tegangan pada permukaan laut, sehingga permukaan air yang tadinya tenang akan terganggu dan timbul riak gelombang kecil diatas permukaan air (Hariyoni dkk, 2013).

$$
\begin{aligned}
\mathrm{R}_{\mathrm{L}} & =\mathrm{Uw} / \mathrm{U}_{\mathrm{L}} \\
\mathrm{Uw} & =\mathrm{R}_{\mathrm{L}} \mathrm{U}_{\mathrm{L}} \\
\mathrm{U}_{\mathrm{A}} & =0,71 \mathrm{Uw}^{1,23}
\end{aligned}
$$

Keterangan:

$\mathrm{R}_{\mathrm{L}} \quad=$ Hubungan antara angin di darat dan di laut

$\mathrm{Uw}=$ Kecepatan angin di darat $(\mathrm{m} / \mathrm{dt})$

$\mathrm{U}_{\mathrm{L}} \quad=$ Kecepatan angin di laut $(\mathrm{m} / \mathrm{dt})$

$\mathrm{U}_{\mathrm{A}} \quad=$ Faktor tegangan angin $(\mathrm{m} / \mathrm{dt})$

\section{Mawar angin}

Mawar angin atau wind rose adalah diagram hasil pengelompokkan angin dan arah angin setiap bulan selama beberapa tahun terakhir berdasarkan arah dan kecepatannya (Nadia, 2013).

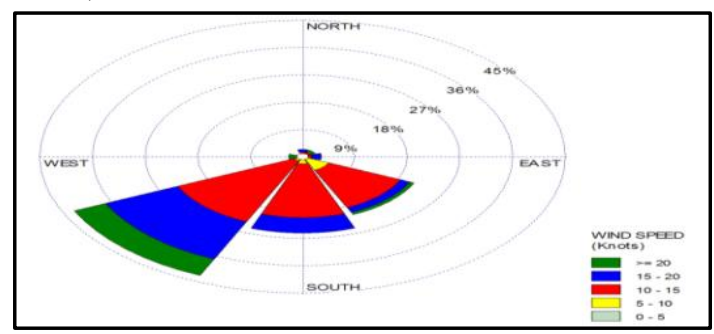

Sumber: Aldin, 2015 
Gambar 1. Mawar-Angin (Wind Rose)

Fetch

$$
\mathrm{F}_{\mathrm{eff}}=\frac{\sum X i \cdot \cos . \alpha}{\cos \cdot \alpha}
$$

Keterangan:

Feff $=$ Fetch rata - rata efektif (Panjang segmen fetch yang diukur dari titik observasi gelombang ke ujung akhir fetch).

$\mathrm{a}=$ Deviasi pada kedua sisi dari arah angin, dengan menggunakan pertambahan $6^{\circ}$ sampai sudut sebesar $42^{\circ}$ pada kedua sisi dari arah angin.

\section{Gelombang}

Gelombang di laut bisa dibangkitkan oleh angin (gelombang angin), gaya tarik matahari dan bulan (pasang surut), letusan gunung berapi atau gempa di laut (tsunami), dan lain sebagainya. Gelombang dapat menimbulkan energi untuk membentuk pantai, menimbulkan arus dan transpor sedimen dalam arah tegak lurus dan sepanjang pantai, serta menyebabkan gayagaya yang bekerja pada bangunan pantai (Mamoto dkk, 2013).

Tabel 1. Klasifikasi Gelombang Menurut Teori Gelombang Linear

\begin{tabular}{|c|c|c|c|}
\hline Keterangan & $\begin{array}{c}\text { Gelombang dilaut } \\
\text { dangkal }\end{array}$ & $\begin{array}{c}\text { Gelombang di laut } \\
\text { transisi }\end{array}$ & $\begin{array}{c}\text { Gelombang di laut } \\
\text { dalam }\end{array}$ \\
\hline $\mathrm{d} / \mathrm{L}$ & $\mathrm{d} / \mathrm{L} \geq 1 / 2$ & $1 / 20<\mathrm{d} / \mathrm{L}<1 / 2$ & $\mathrm{~d} / \mathrm{L} \leq 1 / 20$ \\
\hline Tanh $(2 \mathrm{rd} / \mathrm{L})$ & $\approx 2 \pi d / L$ & $\operatorname{Tanh}(2 \mathrm{~d} / \mathrm{L})$ & $\approx 1$ \\
\hline $\begin{array}{c}\text { Cepat rambat } \\
\text { gelombang }\end{array}$ & $C=\frac{L}{T}=\sqrt{g d}$ & $C=\frac{L}{T}=\frac{g T}{2 \pi} \tanh \left[\frac{2 \pi d]}{L}\right]$ & $C=C_{o}=\frac{L}{T}=\frac{g T}{2 \pi}$ \\
\hline $\begin{array}{c}\text { Panjang } \\
\text { Gelombang }\end{array}$ & $L=T \sqrt{g d}$ & $L=\frac{g T^{2}}{2 \pi} \tanh \left[\frac{2 \pi d}{L}\right]$ & $L=L_{o}=\frac{g T^{2}}{2 \pi}=1,56 T^{2}$ \\
\hline
\end{tabular}

Sumber: Wireksoo, 2005

\section{Refraksi gelombang}

Refraksi terjadi karena adanya pengaruh perubahan kedalaman laut. Di daerah dimana kedalaman air lebih besar dari setengah panjang gelombang, yaitu di laut dalam, gelombang menjalar tanpa dipengaruhi dasar laut. Tetapi di laut transisi dan dangkal, dasar laut mempengaruhi gelombang (Zendrato, Terunajaya 2015) diberikan dengan rumus:

$$
L o=1,56 \times T^{2}
$$

\section{Gelombang laut dalam ekivalen}

Analisis transformasi gelombang sering dilakukan dengan konsep gelombang laut dalam ekivalen, yaitu tinggi gelombang di laut dalam apabila gelombang tidak mengalami refraksi. Tinggi gelombang laut dalam ekivalen diberikan oleh bentuk (Triadmodjo, 1999):

$$
H_{0}^{\prime}=K_{r} H_{0}
$$

Keterangan:

$\mathrm{H}^{\prime}{ }_{0}=$ Tinggi gelombang laut dalam ekivalen $\mathrm{H}_{0}=$ Tinggi gelombang laut dalam $\mathrm{Kr}=$ Koefisien refraksi

\section{Gelombang pecah}

Gelombang yang menjalar dari laut dalam menuju pantai mengalami perubahan bentuk karena adanya pengaruh perubahan kedalaman laut. Pengaruh kedalaman laut mulai terasa pada kedalaman lebih kecil dari setengah kali panjang gelombang (Syahputra, 2014).

\section{Run-up dan run-down gelombang}

Run up gelombang didefinisikan sebagai level pencapaian tertinggi gelombang laut pada sebuah struktur yang mempunyai permukaan miring, diukur secara vertikal dari muka air diam (Still Water Level, SWL). Sedangkan run down gelombang merupakan level pencapaian terendah gelombang laut pada sebuah struktur yang mempunyai permukaan miring, juga diukur secara vertikal dari muka air diam (Refi, 2013).

$$
I r=\frac{\tan \theta}{\left(\frac{H}{L o}\right)^{1 / 2}}
$$

Keterangan:

Ir $=$ Bilangan Irribaren

$\Theta=$ Sudut kemiringan struktur

$\mathrm{H}$ = Tinggi gelombang di lokasi bangunan 
Lo = Panjang gelombang di laut dalam

\section{Fluktuasi muka air laut}

Elevasi muka air laut merupakan parameter sangat penting di dalam perencanaan bangunan pantai (Hariyoni dkk, 2013). Muka air laut berfluktuasi dengan periode yang lebih besar dari periode gelombang angin. Beberapa proses alam yang terjadi dalam waktu yang bersamaan membentuk variasi muka air laut dengan periode panjang. Hariyoni dkk, (2013) juga menjelaskan bahwa elevasi tersebut merupakan penjumlahan dari beberapa parameter yaitu pasang surut, wave setup, wind set-up dan kenaikan muka air laut karena pemanasan global.

\section{Pasang surut}

Pasang surut adalah fluktuasi muka air laut akibat adanya gaya tarik benda-benda langit, terutama matahari dan bulan terhadap massa air laut di bumi, Perubahan pasang surut seiring dengan perubahan posisi diantara ketiganya. (Wijaya dan Suntoyo, 2013).

Christina dan Putuhena, (2009) menjelaskan pasang surut di berbagai daerah dapat dibedakan dalam empat tipe, yaitu:

1. Diurnal Tide (Pasang Surut Harian Tunggal), yang terjadi satu kali pasang dan satu kali surut dalam satu hari satu malam (12 jam 24 menit).

2. Semi Diurnal Tide (Pasang Surut Harian Ganda), yaitu terjadi dua kali pasang dan dua kali surut dalam satu hari satu malam (kurang lebih 24 jam).

3. Mixed Tide Prevailing Semi Diurnal (Pasang Surut Campuran Condong Ke Harian Ganda) dalam satu hari terjadi dua kali pasangan dan dua kali surut.

4. Mixed Tide Prevailing Diurnal (Pasang Surut Campuran Condongan Ke Harian Tunggal)

Kenaikan muka air karena gelombang (wave set up)
Gelombang yang datang dari laut menuju pantai menyebabkan fluktuasi muka air di daerah pantai terhadap muka air diam. Pada waktu gelombang pecah, akan terjadi penurunan elevasi muka air rerata terhadap elevasi muka air diam di sekitar lokasi gelombang pecah. Kemudian dari titik dimana gelombang pecah permukaaan permukaan air rerata miring ke atas ke arah pantai. Naiknya muka air laut disebut wave set up, sedangkan turunnya muka air laut dikenal dengan wave set down (Christina dan Putuhena, 2009).

\section{Kenaikan muka air karena angin (wind set up)}

Angin dengan kecepatan besar (badai) yang terjadi diatas permukaan laut bisa membangkitkan fluktuasi muka air laut yang besar di sepanjang pantai jika badai tersebut cukup kuat dan daerah pantai dangkal dan luas. Penentuan elevasi muka air rencana selama terjadinya badai adalah sangat kompleks yang melibatkan interaksi antara angin dan air, perbedaan tekanan atmosfer dan beberapa parameter lainnya. Perbedaan tekanan atmosfer selalu berkaitan dengan perubahan arah dan kecepatan angin; dan angin tersebut yang menyebabkan fluktuasi muka air laut (Zendrato, Terunajaya 2015).

\section{Design Water Level (DWL)}

Elevasi muka air rencana tergantung pada pasang surut, wave set, tsunami dan pemanasan global. Mengingat bahwa kemungkinan terjadinya secara bersamaan adalah sangat kecil. Selain itu kepentingan bangunan ini tidak sangat tinggi. Oleh karena itu elevasi muka airrencana hanya didasarkan pada pasang surut, wave set-up dan pemanasan global. Berikut adalah rumus mencari nilai DWL (Wijaya, 2015):

$\mathrm{DWL}=\mathrm{HWL}+\mathrm{SW}+\Delta \mathrm{h}+\mathrm{SLR}$

Keterangan:

DWL = tinggi muka air rencana 
$H W L=$ high water level (muka air pasang tertinggi)

SLR = sea level rise (kenaikan muka air laut)

SW = wave set-up

$\Delta h \quad=$ kenaikan elevasi muka air

\section{Pemecah gelombang lepas pantai}

Pengurangan tenaga gelombang yang menghantam pantai dapat dilakukan dengan membangun pemecah gelombang sejajar pantai. Gelombang yang datang akan menghantam pemecah gelombang akan pecah pada suatu tempat agak jauh dari pantai, sehingga energy gelombang yang sampai di pantai cukup kecil (Hidayat, 2006).

\section{Bangunan pengaman pantai}

Bangunan pengaman pantai merupakan konstruksi yang dibangun sejajar atau tegak lurus dengan garis pantai yang berfungsi untuk melindungi pantai terhadap kerusakan karena serangan gelombang dan arus. Hidayat (2006) menjelaskan bahwa bangunan laut dan pantai yang dibangun dapat digunakan untuk melindungi pantai terhadap kerusakan karena serangan gelombang dan arus maupun untuk kepentingan lainnya seperti fasilitas untuk menarik wisatawan khususnya untuk daerah pantai wisata.

\section{Klasifikasi bangunan}

Sesuai dengan fungsinya, bangunan pantai dikelompokkan dalam tiga kelompok, yaitu (Triatmodjo, 2010 dalam Wijaya, 2015):

a. Konstruksi yang dibangun di pantai dan sejajar dengan garis pantai. Yang termasuk kelompok ini adalah dinding pantai (revetment).

b. Konstruksi yang dibangun kira-kira tegak lurus pantai dan menyambung ke pantai. Yang termasuk kelompok ini adalah groin (groyne) dan jetty.

c. Konstruksi yang dibangun lepas pantai dan kira-kira sejajar dengan garis pantai.
Yang termasuk kelompok ini yaitu pemecah gelombang (breakwater).

\section{Revetment}

Revetment adalah bangunan yang memisahkan daratan dan perairan pantai, yang terutama berfungsi sebagai pelindung pantai terhadap erosi dan limpasan gelombang (overtopping) ke darat. Daerah yang dilindungi adalah daratan tepat di belakang bangunan. Dinding pantai biasanya berbentuk dinding vertikal, sedang revetment mempunyai sisi miring. Bangunan ini ditempatkan sejajar atau hampir sejajar dengan garis pantai, dan bisa terbuat dari pasangan batu, beton, tumpukan pipa beton, turap, kayu atau tumpukan batu (Kakistina, 2009).

\section{Breakwater}

Pemecah gelombang adalah bangunan yang digunakan untuk melindungi daerah perairan dari gangguan gelombang. Pemecah gelombang dibedakan menjadi dua macam yaitu pemecah gelombang sambung pantai dan lepas pantai. Tipe pertama digunakan untuk perlindungan perairan pelabuhan, sedangkan tipe kedua untuk perlindungan pantai terhadap erosi (Triatmodjo, 2008).

\section{Material pembentuk breakwater}

Material dalam pembuatan breakwater ada beberapa jenis yang bisa digunakan untuk membuat lapisan-lapisan, diantaranya adalah:

a. Batu alam (Querry Stone)

Batu alam adalah bahan yang paling sering digunakan sebagai unti lapis pelindung karena tidak memerlukan pencetakan seperti pada batu lapis pelindung buatan. (Refi, 2013).

b. Pelindung buatan (Artificial Armour Unit)

Batu alami kadang-kadang susah didapat dengan massa yang berat dalam jumlah yang sangat banyak,untuk mengatasinya maka dibuat batu buatan 
(artificial) dari beton dengan bentuk tertentu. Batu buatan ini bisa juga berupa tetrapod, tribar, hexapod, dolos, A-jack, dan sebagainya (Refi, 2013).

\section{Pasang surut air laut}

Menurut Pariwono (1989), fenomena pasang surut diartikan sebagai naik turunnya muka laut secara berkala akibat adanya gaya tarik benda-benda angkasa terutama matahari dan bulan terhadap massa air di bumi. Sedangkan menurut Dronkers (1964) pasang surut laut merupakan suatu fenomena pergerakan naik turunnya permukaan air laut secara berkala yang diakibatkan oleh kombinasi gaya gravitasi dan gaya tarik menarik dari benda-benda astronomi terutama oleh matahari, bumi dan bulan.

\section{METODE PENELITIAN}

\section{Lokasi Penelitian}

Penelitian ini dilakukan di Pantai Malabero Kota Bengkulu.

\section{Pengumpulan data}

a. Data primer berupa data tinggi gelombang dan dimensi bangunan lama.

b. Data sekunder berupa data angin BMKG selama 10 tahun dari tahun 2007-2016, data pasang surut 10 tahun dan peta toporafi.

Tahapan pelaksanaan penelitian

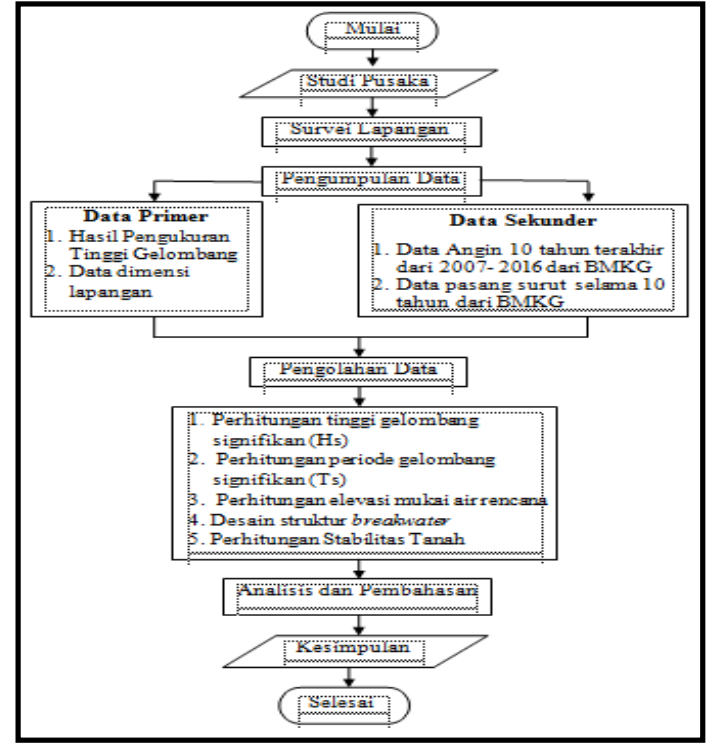

Gambar 2. Bagan Alir Penelitian

\section{HASIL DAN PEMBAHASAN}

\section{Perhitungan struktur}

Analisis berat lapis lindung beakwater menggunakan batu alam

Analisis berat batu lindung untuk bagian ujung atau kepala bangunan breakwater dengan keadaan gelombang belum pecah $(2,69$ meter $)$.

(menggunakan beton batu pecah):

Lapisan pelindung luar:

$\mathrm{W}=\frac{2,65 \times 2,69^{3}}{2 \times\left(\frac{2,65}{1,03}-1\right)^{3} \times 2}=3,31$ ton

Lapisan pelindung kedua:

$\frac{\mathrm{W}}{10}=\frac{3,31}{10}=0,331$ ton $=331$ kilogram

Berat batu lapis inti (core):

$\frac{\mathrm{W}}{200}=\frac{3,31}{200}=0,016$ ton $=16$ kilogram

Perhitungan berat lapisan lindung breakwater bagian lengan

Analisis berat batu lindung untuk bagian lengan atau badan bangunan breakwater dengan keadaan gelombang sudah pecah (3,17 meter).

Lapisan pelindung luar: 
$\mathrm{W}=\frac{2,65 \times 3,17^{3}}{2,8 \times\left(\frac{2,65}{1,03}-1\right)^{3} \times 2}=3,87$ ton

Lapisan pelindung kedua:

$\frac{\mathrm{W}}{10}=\frac{3,87}{10}=0,387$ ton $=387$ kilogram

Berat batu lapis inti (core) :

$\frac{\mathrm{W}}{200}=\frac{3,87}{200}=0,019$ ton $=19$ kilogram

Elevasi $=\mathrm{HWL}+\mathrm{Ru}+0,5$

$=1,5+3,55+0,5$

$=5,55 \mathrm{~m}$

$\mathrm{H}_{\text {bangunan }}=$ Elevasi $_{\text {puncakbangunan }}-$ Elevasi $_{\text {dasarlaut }}$

$=+5,55-(-3,5)$

$=9,05 \mathrm{~m}$

\section{Analisis lebar puncak}

Bagian ujung atau kepala :

$B=n \times K_{\Delta}\left[\frac{W}{\gamma_{r}}\right]^{1 / 3}=3 \times 1,15\left[\frac{3,31}{2,65}\right]^{1 / 3}=3,71 \mathrm{~m}$

Bagian lengan atau badan :

$B=n \times K_{\Delta}\left[\frac{W}{\gamma_{r}}\right]^{1 / 3}=3 \times 1,15\left[\frac{3,87}{2,65}\right]^{1 / 3}=3,91 \mathrm{~m}$

Jadi lebar puncak breakwater adalah 3,71 m untuk bagian ujung atau kepala, dan 3,91 m untuk bagian lengan atau badan.

\section{Analisis tebal lapis lindung}

Lapisan pelindung luar:

$t=n \times K_{\Delta}\left[\frac{W}{\gamma_{r}}\right]^{1 / 3}=2 \times 1,15\left[\frac{3,31}{2,65}\right]^{1 / 3}=2,48 m$

Lapisan pelindung kedua:

$t=n \times K_{\Delta}\left[\frac{W}{\gamma_{r}}\right]^{1 / 3}=2 \times 1,15\left[\frac{0,331}{2,65}\right]^{1 / 3}=1,15 m$

\section{Pelindung kaki}

Pelindung kaki berfungsi untuk melindungi tanah pondasi terhadap erosi yang timbul oleh serangan gelombang besar. Batu pelindung terdiri dari batu pecah dengan berat sebesar W/10. Perhitungan sebelumnya didapat berat lapis pelindung utama bagian kepala dengan lengan masing-masing 3,31 ton dan 3,87 ton.

1. Berat batu pelindung kaki untuk bagian kepala:

$\frac{\mathrm{W}}{10}=\frac{3,31}{10}=0,331 \mathrm{ton}=331 \mathrm{~kg}$

2. Berat batu pelindung kaki untuk bagian lengan:

$\frac{\mathrm{W}}{10}=\frac{3,87}{10}=0,387 \mathrm{ton}=387 \mathrm{~kg}$

3. Lebar pelindung kaki dapat dihitung dengan rumus:

$\mathrm{B}=2 \times \mathrm{H}$

Perhitungan lebar kaki bagian kepala:

$$
\begin{aligned}
\mathrm{B} & =2 \times 2,69 \\
& =5,38 \text { meter }
\end{aligned}
$$

Perhitungan lebar pelindung kaki bagian lengan:

$$
\begin{aligned}
\mathrm{B} & =2 \times 3,17 \\
& =6,34 \text { meter }
\end{aligned}
$$

4. Perhitungan tinggi pelindung kaki bagian kepala

$$
\begin{aligned}
T & =2 \times 1,02\left[\frac{3,31}{2,65}\right]^{1 / 3} \\
& =2,19 \mathrm{~m} \\
T & =2 \times 1,02\left[\frac{3,87}{2,65}\right]^{1 / 3} \\
= & 2,31 \mathrm{~m}
\end{aligned}
$$

\section{Analisis jumlah batu lindung bagian} kepala bangunan breakwater

$N=10 \times 2 \times 1,15\left[1-\frac{37}{100}\right] \times\left[\frac{2,65}{3,31}\right]^{2 / 3}=12,5 \approx 13$

Analisis jumlah batu lindung bagian lengan atau badan bangunan breakwater

$N=10 \times 2 \times 1,15\left[1-\frac{37}{100}\right] \times\left[\frac{2,65}{3,87}\right]^{2 / 3}=11,26 \approx 12$

Jadi, hasil perhitungan jumlah butir tiap satuan luas $10 \mathrm{~m}^{2}$ adalah 13 butir untuk 
bagian ujung atau kepala, dan 12 butir untuk bagian lengan atau badan.

\section{Stabilitas struktur}

Perhitungan gaya gelombang dinamis:

$$
\begin{aligned}
\mathrm{Rm} & =1 / 2 \times \mathrm{\gamma}_{\mathrm{a}} \times \mathrm{ds} \times \mathrm{Hb} \\
& =1 / 2 \times 1,03 \times 2,69 \times 3,17 \\
& =4,39 \text { ton }
\end{aligned}
$$

Momen gaya gelombang dinamis:

$$
\begin{aligned}
\mathrm{Mm} & =\mathrm{Rm} \times(\mathrm{ds}+\mathrm{Hb} / 2) \\
& =4,39 \times(2,69+3,17 / 2) \\
& =18,77 \mathrm{tm}
\end{aligned}
$$

\section{Perhitungan gaya hidrostatis}

Gaya gelombang dinamis:

$$
\begin{aligned}
\text { Rs } & =1 / 2 \times \gamma_{a} \times(d s+H b)^{2} \\
& =1 / 2 \times 1,03 \times(2,69+3,17)^{2} \\
& =17,68 \text { ton }
\end{aligned}
$$

Momen gaya hidrostatis:

$$
\begin{aligned}
\text { Ms } & =1 / 6 \times \gamma_{\mathrm{a}} \times(\mathrm{ds}+\mathrm{Hb})^{3} \\
& =1 / 6 \times 1,03 \times(2,69+3,17)^{3} \\
& =34,54 \mathrm{tm}
\end{aligned}
$$

\section{Perhitungan gaya dan momen}

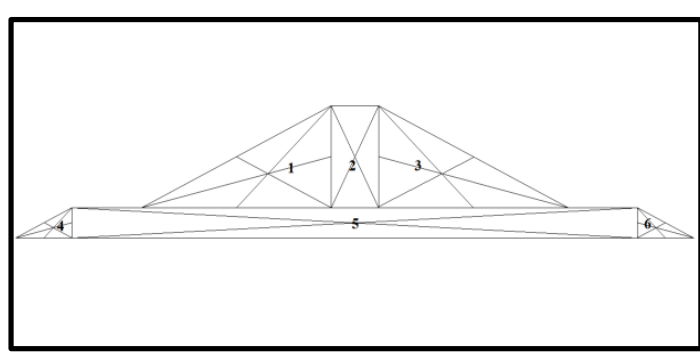

Gambar 3. Gambar gaya yang bekerja pada breakwater

Tabel 4.7 Perhitungan Gaya Dan Momen Yang Terjadi (Kepala)

\begin{tabular}{|c|c|c|c|c|c|c|}
\hline GAYA & LUAS & $\mathrm{V}$ & $\mathrm{H}$ & LENGAN & MV & MH \\
\hline 1 & 47.06 & 124.71 & & 19.57 & 2440.53 & \\
\hline 2 & 25.45 & 67.44 & & 26.34 & 1776.48 & \\
\hline 3 & 47.06 & 124.71 & & 33.10 & 4127.83 & \\
\hline 4 & 4.80 & 12.71 & & 2.92 & 37.1122 & \\
\hline 5 & 96.16 & 254.83 & & 26.34 & 6712.27 & \\
\hline 6 & 4.80 & 12.71 & & 49.75 & 632.306 & \\
\hline Rs & & & 17.68 & & & 34.54 \\
\hline Rm & & & 4.39 & & & 18.77 \\
\hline Jumlah & & $\mathbf{5 9 7 . 1 1}$ & $\mathbf{2 2 . 0 7}$ & & $\mathbf{1 5 7 2 6 . 5}$ & $\mathbf{5 3 . 3 1}$ \\
\hline
\end{tabular}

Keterangan:

$\mathrm{V}$ : Gaya vertikal akibat berat sendiri

$$
\text { (V = luas x y batu) }
$$

$\mathrm{H}$ : Gaya horizontal

MV : Momen vertikal ( $\mathrm{MV}=\mathrm{V}$ x lengan)

MH : Momen horizontal

\section{Kontrol stabilitas keseluruhan konstruksi}

$$
\begin{aligned}
\text { Stabilitas Guling } & =\frac{\sum \mathrm{MV}}{\sum \mathrm{MH}} \quad>2 \\
& =\frac{15726,5}{53,31}=295>2 \mathrm{OKE} ! \\
\text { Stabilitas Geser } & =\frac{\sum \mathrm{Vx} \mu_{\mathrm{s}}}{\sum \mathrm{H}}>1,5 \\
= & \frac{597,11 \times 0,4=10,82}{22,07}
\end{aligned}
$$

\section{KESIMPULAN}

Kesimpulan yang dapat diambil dari data hasil penelitian mengenai perancangan breakwater sisi miring sebagai upaya mengantisipasi limpasan air laut pada bangunan revetment di pantai malabero yaitu hasil perhitungan breakwater menggunakan batu pecah mempunyai elevasi puncak 5,55 $\mathrm{m}$, lebar puncak 3,71 m pada bagian kepala dan 3,91 m pada bagian lengan. Berat unit lapis pelindung breakwater batu pecah bagian kepala $\mathrm{W}=3,31$ ton, $\mathrm{W} / 10=331 \mathrm{~kg}$, $\mathrm{W} / 200=16 \mathrm{~kg}$ dan bagian lengan $\mathrm{W}=3,87$ ton, $\mathrm{W} / 10=387 \mathrm{~kg}, \mathrm{~W} / 200=19 \mathrm{~kg}$. Perencanaan ini telah memenuhi syarat stabilitas terhadap bahaya guling sebesar $295>2$ dan geser sebesar 10,82 > 1,5.

\section{DAFTAR PUSTAKA}

Christina, J., dan Putuhena, M, V. 2009. Stability Evaluation of Sea Wall Construction at Erie Village Location Nusaniwe District Amboina City. Jurnal Teknologi. Vol.6, No.2. UKIM. Ambon.

Dronkers, J.J. 1964. Tidal Computations in Rivers and Coastal Waters. Amsterdam: North-Holland Publishimg Company. 
Hariyoni., Sisinggih, D., dan Marsudi, S. 2010. Studi Perencanaan Bangunan Pengendalian Akresi dan Abrasi di Pantai Tanjungwangi Kabupaten Banyuwangi. Jurnal Teknik Pengairan, Universitas Brawijaya, Malang.

Hidayat, N. 2006. Konstruksi Bangunan Laut dan Pantai sebagai Alternatif Perlindungan Daerah Pantai. Jurnal SMARTek. Vol.4. No.1. Universitas Tadulako, Palu.

Mamoto, J, D., Jasin, M, I., d a n Tawas, H, J. 2013. Perencanaan Jetty di Muara Sungai Ranoyapo Amorang. Jurnal Sipil Statik. Vol.1. No.6. Universitas Sam Ratulangi, Manado.

Nadia, P. 2013. Analisis Pengaruh Angin terhadap Tinggi Gelombang pada Struktur Bangunan Breakwater di Tapak Paderi Kota Bengkulu. Skripsi, Program Studi Teknik Sipil. Universitas Bengkulu.

Pariwono, J.I. 1989. Gaya Penggerak Pasang Surut dalam Pasang Surut. Ed. Ongkosongo, O.S.R. dan Suyarso. Jakarta: P3O-LIPI.

Refi, A. 2013. Analisis Breakwater Pelabuhan Teluk Bayur dengan Menggunakan Batu Alam, Tetrapod, dan A-Jack. Jurnal Momentum, Volume 15. No. 2. Institut Teknologi Padang.

Syahputra, D. 2014. Analisis Struktur Bangunan Breakwater Tipe Campuran (Studi Kasus di Tapak Paderi Kota Bengkulu). Skripsi. Program Studi Teknik Sipil. Universitas Bengkulu.
Triatmodjo, B. 1999. Teknik Pantai. Beta Offset, Yogyakarta.

Triatmodjo, B. 2010. Perencanaan Bangunan Pantai. Beta Offset, Yogyakarta.

Umar. 2011. Kajian Pengaruh Gelombang terhadap Kerusakan Pantai Matang Danau Kabupaten Sambas. Jurnal Teknik Sipil Untan. Vol.2. No.2. Universitas Tanjungpura.

Wijaya, H. T. 2015. Analisis Bangunan Revetment yang Ekonomis untuk Samudera Lepas (Studi Kasus Pantai Pondok Kelapa Bengkulu Tengah).Skripsi. Program Studi Teknik Sipil. Universitas Bengkulu, Bengkulu.

Wijaya, H. G., dan Suntoyo, W. 2013. Studi Perlindugan Pipeline PT. Pertamina Gas di Pesisir Indramayu, Jurnal Teknik Pomits. Vol.2. No.2. Institut Teknologi Sepuluh Nopember.

Wirekso, U.L., dan Inayah, N. 2005. Perencanaan Bangunan Pengaman Pantai di Daerah Mundu-Balongan (dengan Menggunakan Bantuan Program Genesis). Skripsi. Program Studi Teknik Sipil. Universitas Diponogoro.

Zendrato, N.L.H., Terunajaya. 2015. Analisis Efektivitas Penggunaan Breakwater dengan Lapis Pelindung Bambu dan Tetrapod untuk Mereduksi Energi Gelombang Laut di Pelabuhan Kuala Tanjung. Jurnal Teknik Sipil. Universitas Sumatera Utara, Medan. 
ISSN 2086-9045 